\title{
Experience of Studying Innovative Behavior of Youth in Russia
}

\author{
Valentina Lukina ${ }^{a, 1}$, Tuyaara Sidorova ${ }^{\text {a }}$, Maria Nafanailova ${ }^{a}$ \\ ${ }^{a}$ Institute of Psychology, North-Eastern Federal University, Russia \\ 1 lukina_v@mail.ru
}

\begin{abstract}
Transformations in society need to raise the level of their economic consciousness. The problem is that the level of innovation remains low. The article presents the description of the innovative economic behaviour study. A survey was done on students from different courses. The experiment was aimed at studying the group interaction factors in the formation of innovative behaviour. We proceeded from the proposition that innovativeness is a derivative of individual creativity and external factors, in particular, the factor of group interaction. We assume that factors of group interaction are more important for the development of innovative economic behavior. The case study have a several stages. First, the level of individual creativity and innovativeness was studied. Then the subjects received a task during the week. The results showed that the level of individual creativity is not a sufficient condition for the manifestation of innovative behaviour. Group factors play an important role in it as well. More importantly for team work is intra-group cognitive and social processes. In addition, the results of the case study, suggest that innovation is a skill that can be developed.
\end{abstract}

\section{Keywords}

Innovative Economic Behavior; Creativity; Innovativeness; Students

\section{INTRODUCTION}

Transformation of the Russian economy, its transition to an innovative way of development cannot be carried out without human resources capable of implementing an innovative breakthrough, with the necessary professional and personal qualities, and economic behavior should be characterized by activity, readiness for innovation.

Economic behavior is a subject of study of several sciences: economics, sociology, psychology. The psychological approach, unlike the economic one, presupposes limited rational choice. Specificity of the subject of psychology is to study such aspects of a person's financial behavior that go beyond logical choice.

\section{LITERATURE REVIEW}

At the moment, we can identify several research areas performed by the Russian psychologists. The general methodological bases of economic 
consciousness and innovativeness are networks, which are characterized by the developed by Zhuravlev \& Kupreychenko intensification of both internal and external (2007); Karnyshev (2011); Klochko \& links. Accordingly, their tasks and problems Galazhinsky (2009); Neverov (2010); are interdisciplinary, and cohesive Yagolkovsky (2010), etc. teamwork is needed to solve them.

The innovation process is considered as a series of stages extended in time Cummings \& O'Connell (1978), each step involves its tasks.

Communicative skills, skills of teamwork and cooperation become key competencies.

Analyzing the team's collaborative

In this paper, by innovative economic behavior, we understand creative forms of human behavior under the influence of economic alternatives, which contribute to economic efficiency improvement. In other words, innovative behavior is held to imply the originality of the way of implementing economic behavior in the situation of profit extraction. The main characteristics of such behavior are 1) creativity or originality of the way the idea is realized; 2) fluency (number of views) and flexibility (versatility of ideas); 3) economic efficiency.

In the history of the study of innovative processes, one can observe a change in several paradigms of understanding their essence. The initially developed model of innovation processes has undergone significant changes and became more complex and branched. Modern models resemble interworking systems that operate on the principle of work we can be premised on a collaborative problem-solving (CPS) method, which represents a complicated process when two or more people try to solve a problem by sharing their understanding and efforts needed to do so by combining knowledge, skills, and attempts to reach a decision (Chang et al., 2017). The method assumes three main competencies: establishing and maintaining a common understanding; taking appropriate measures to solve the problem; creation and maintenance of the team.

These competencies arise from a combination of two interrelated processes: social and cognitive. That is, to understand and solve a problem, students should have the skills of interaction, communication as well as the skills to regulate actions to solve the problem (Hesse et al., 2015). The cognitive process (the ability to solve 
problems) implies studying and testing is to identify the level of individual understanding of the content of the creativity of participants. To assess problem, the presentation, and creativity, we used three methods: formulation of the hypothesis, the planning "Drawing Completion Test", a shortened of a strategy for solving the problem, version of the Torrance Creativity Test monitoring results and reflection. Social (Tunik, 1998), the questionnaire "Selfprocesses are aimed at establishing mutual appraisal scale of innovative personality understanding, taking appropriate qualities" by Lebedeva \& Tatarko (2009), measures to solve the problem "Questionnaire for assessing the (coordination), as well as the formation of predominant type of readiness for a team and supporting it. The method of innovation" by Zagashev (2010).

joint problem solving facilitates the Torrance Creativity Test 'Drawing integration of these two processes. Completion Test' is a set of pictures with a

\section{RESEARCH METHOD}

The sum and substance of the experiment were that students had to earn some money in one week, having 100 rubles as initial capital. To successfully solve this problem, students needed to demonstrate the ability to see and articulate the need, unconventional thinking, entrepreneurial attitude and the ability to work in teams.

The experiment was carried out in three stages. At the first stage, group specific set of elements (lines), using which a testee need to finish the picture to some meaningful image. Drawings are evaluated according to the following criteria: originality, flexibility, fluency, and elaboration.

The questionnaire developed by Lebedeva \& Tatarko consists of 12 questions concerning which the overall innovation index is assessed. The methodology also includes subscales: creativity, a risk for success, futureorientated thinking.

testing was conducted. The purpose of 
Table 1. Results of the task execution by the teams

\begin{tabular}{|c|c|c|c|c|}
\hline No & Team & $\begin{array}{c}\text { Earned } \\
\text { sum, rub }\end{array}$ & $\begin{array}{c}\text { Number } \\
\text { of ideas }\end{array}$ & $\begin{array}{c}\text { The originality of ideas, } \\
\text { solving the problem }\end{array}$ \\
\hline 1 & $\begin{array}{c}\text { Group } \\
1\end{array}$ & 500 & 1 & $\begin{array}{c}\text { They bought yarn for 100rub, made } \\
\text { teddy bears and sold them. }\end{array}$ \\
\hline 2 & $\begin{array}{c}\text { Group } \\
2\end{array}$ & 1450 & 5 & $\begin{array}{l}\text { 1. Doing Implementation of the } \\
\text { Students' Work. } \\
\text { 2. Use of their workforce (work on the } \\
\text { side) }\end{array}$ \\
\hline 3 & $\begin{array}{c}\text { Group } \\
3\end{array}$ & 64 & 1 & $\begin{array}{l}\text { 3laying cards. } \\
\text { 4. Playing chess. } \\
\text { 5. Voluntary donations for "free hugs". }\end{array}$ \\
\hline 4 & $\begin{array}{c}\text { Group } \\
4\end{array}$ & 300 & 1 & Retail (reselling noodles). \\
\hline 5 & $\begin{array}{c}\text { Group } \\
5\end{array}$ & 800 & 1 & Singing and playing guitar. \\
\hline
\end{tabular}

Zagashev when assessing readiness for innovation, distinguishes 7 types of behavior: 1) willingness to follow a leader; 2) readiness, subject to material compensation; 3) willingness, subject to a possibility to take responsibility for innovation; 4) readiness, subject to personal and professional self-realization; 5) readiness, provided there are no major changes; 6) readiness based on experience; 7) readiness on the basis of positive emotional perception of everything new. The questionnaire includes 56 statements, and a respondent should express his/her attitude towards them.

In total 74 students participated in the experiment, $19 \%$ of them were men, and $81 \%$ of them were women. Age composition: 52 students at the ages from 18 to 21,18 people at the ages from 22 to 25 , two people over 25 years.

The experiment was carried out on two different samples. In the first sample, there were 41 students, $24 \%$ of them were men, and $76 \%$ of them were women. Thirty people were at the ages from 18 to 21 , ten people were at the ages from 22 to 25 , one person was older than 25.

In the second sample, there were 33 students, of which $12 \%$ were men and $88 \%$ were women. Twenty-two respondents were at ages from 18 to 21 , eight people were at the ages from 22 to 25 , three people were older than 25 .

Testing was conducted in the group. Based on the test results, groups of 7-8 
people were formed. We tried to develop the groups in such a way that they did not differ much in terms of creativity, i.e., in each group, there were participants with high, medium and low levels of creativity.

At the second stage, group work was aimed at activating its work, discussion of the problem, during which the members of the group jointly discussed the options for solving it. As the main task, the students were offered a well-known entrepreneurial task "Imagine that your group has 100 rubles, your task is to multiply these 100 rubles in one week". The discussion was conducted by brainstorming. After the announcement of the assignment, the participants worked individually- all possible solutions to the problem the participant recorded on a separate paper. The individual stage of work was limited to 10 minutes. Then the participants were invited to team up and continue the discussion. The group considered the options proposed by each participant.

During the discussion, the choices were further developed and revised. As a result of the group work, each group had to choose only three options discussed, among which there were the most successful in their opinion, the most unsuccessful and average. Then the groups presented their ideas.

The process of discussing the problem was recorded by the observers, and it also was recorded on a video. The participants of the experiment were notified in advance that the process of discussion would be fixed by the observers and recorded with the help of the video equipment. To fix the results, we used R. Bells' observation scheme, which allowed us to track the interaction of people in the group. R.Beils identifies 12 categories of interaction, grouped by different domains: positive emotions, negative emotions, articulating the problem and solving the problem. As a recorded observation, only verbal interactions of the participants were accepted. 
Table 2. Indicators of innovativeness in groups

\begin{tabular}{|c|c|c|c|c|}
\hline Team & $\begin{array}{c}\text { Overall } \\
\text { innovation index }\end{array}$ & $\begin{array}{c}\text { Creativit } \\
\mathbf{y}\end{array}$ & $\begin{array}{c}\text { Risk for } \\
\text { success }\end{array}$ & $\begin{array}{c}\text { Future-oriented } \\
\text { thinking }\end{array}$ \\
\hline Group 1 & 3,2 & 3,41 & 2,97 & 3,2 \\
\hline Group 2 & 3,4 & 3,5 & 3,1 & 3,6 \\
\hline Group 3 & 3,68 & 3,91 & 3,38 & 3,75 \\
\hline Group 4 & 3,37 & 3,16 & 3,41 & 3,53 \\
\hline Group 5 & 2,92 & 3,14 & 2,68 & 2,93 \\
\hline
\end{tabular}

At the end of the session, the groups The originality of the ideas realized meant received the same task, but this time they the ability to look at the problem from the had to perform it in reality. Thus, each group had 100 rubles and one week at their disposal. A week later we had a other side, the ability to solve it in an unconventional way.

meeting with the participants; each group presented the results of their work. We also discussed how the task was completed; the students expressed their thoughts and feelings.

\section{RESULT AND DISCUSSION}

The main purpose of the experiment was to identify factors that affect the economic behavior of team members. We analyzed test methods, results of the assignment, protocols for monitoring the discussion of the problem in the group and video materials.

The results (see Table 1). The following criteria were chosen for evaluation: the amount of money earned in one week, the number of ideas worked out

The general results show that among the proposed and implemented ideas, there were often common ways of earning money. However, the participants of Group 2 were more rational. They independently decided to work out several variants, suggesting the solution to the problem in different ways.

We compared the results of the assignment with the results using the method by Lebedeva \& Tatarko (Table 2). We assumed that the highest scores would be earned by Group 2, but we were wrong, Group 2 showed average results.

In terms of the overall innovativeness index, Group 3, earning the least, showed the highest index. This group showed high rates on creativity and future-orientated simultaneously, the originality of the ideas. to use its potential. 
Table 3. The number of observations

\begin{tabular}{|l|c|c|c|c|c|}
\hline \multicolumn{1}{|c|}{ Categories } & Group 1 & Group 2 & Group 3 & Group 4 & Group 5 \\
\hline Positive emotions area & 8 & 21 & 29 & 12 & 6 \\
\hline $\begin{array}{l}\text { Problems definition } \\
\text { area }\end{array}$ & 35 & 25 & 44 & 20 & 14 \\
\hline Problems solving area & 14 & 14 & 8 & 15 & 9 \\
\hline Negative emotions area & 6 & 3 & 26 & 3 & 9 \\
\hline
\end{tabular}

The analysis of the group discussions interacted in the problem-raising area, monitoring protocols showed significant much more than in Group 2 (44). At the differences in the behavior of the same time, more interactions were participants in more 'successful' groups. observed in the area of negative emotions

Analyzing the protocol data, we (26) and comparatively little in the gathered that Group 2, which was more problem-solving area (8).

successful in performing the task, differs It should be noted that not all groups from other groups in demonstrating more completed the assignment together. In positive emotions during the discussion Group 1, the task was performed by only (21, here and below these are the number one participant. The analyzing process of of recorded interactions) and very few interaction found that the group was negative ones (3). Quite a lot of mainly focused on cognitive processes, participants of the group interacted in the showed less emotion, both positive and area of defining the problem (25).

Comparing the results of Group 2 and Group 4, we can see that the distribution of interactions across areas seems to be also dominated by positive emotions in both problems posing and problem-solving areas. We can assume that the group did not have enough dynamics; this is a question for further reflections.

Interestingly, Group 3, which earned less money, gave quite a lot of positive emotions (29), and the participants actively negative.

Summarizing the results of the experiment, it can be noted that the participants showed entrepreneurial behavior. Taking into account that innovative behavior is a certain process, which includes several stages, it can be assumed that when performing the assignment, participants could show innovativeness at different stages. So, for example, it could be an original idea or an original way of implementing a template 
idea. Analyzing the ideas suggested by the participants, we see that already at the stage of generating ideas there are some limitations that make it difficult to look at the problem from the other side, with other eyes.

Thus, to successfully solve the problem in the group, both cognitive and social processes must simultaneously develop. Social processes should be aimed at supporting, encouraging, understanding, which contributes to the establishment of a favorable socio-psychological climate, the creation of an "environmentally friendly", safe atmosphere in the group. The results show that, for the group to be successful, the participants should not only formulate problems and suggest ideas for its solution, but also pay attention to converting understanding into concrete actions to achieve results.

We found that in our case, more important was not the experiment itself, but its aftereffect, the processes that were launched. The feedback received from the participants showed that the experiment aroused great interest among students and most importantly, the participants noted an increase in motivation, activation of thinking aimed at searching. Already after the experiment, new ideas for implementation emerged; there were a desire and interest in trying and mastering new forms of behavior. That is, the experiment itself as a form of teaching innovative behavior gave its results. Thus, innovation is most likely a skill, an ability that can be developed.

\section{ACKNOWLEDGMENT}

The article prepared by Russian Foundation for Basic Research (RFBR), Project No. 17-16-14006.

\section{REFERENCES}

Chang C. J., Chang, M. H., Chiu, B. H., Liu, C. C., Fan, Chiang S. H., Wen, C. T., Hwang, F. K., Wu, Y. T., Chao, P. Y., Lai C. H., Wu, S. W., Chang, C. K., Chen, W. (2017). An analysis of student collaborative problem solving activities mediated by collaborative simulations. Computers \& Education, (114), pp. 222-235,

Cummings, L. K., O'Connell, M. J. (1978). Organizational innovation: A model and needed research. Journal of Business Research, Vol. 6, pp. 33-50.

Hesse, F., Care, E., Buder, J., Sassenberg, K., \& Griffin, P. (2015). A framework for teachable collaborative problem solving skills. Assessment and teaching 
of 21st century skills: Methods and Approach. New York: Springer, pp. 3756.

Karnyshev, A. D. (2011). Social and economic psychology. Irkutsk: Publishing House of Belarusian State University of Economic.

Klochko, V. E., \& Galazhinsky, E. V. (2009). Psikhologiya innovatsionnogo povedeniya [Psychology of innovative behavior]. Tomsk: Tomsk State University.

Lebedeva, N. M., Tatarko, A. N. (2009) Social capital: theory and psychological research. Moscow: RUDN.

Neverov, A. N. (2010). Economic Psychology of Innovation and the Concept of the Noosphere Economy. Psychology and Economics, Vol. 3(1), pp. 32-41.

Tunik, E. E. (1998). Diagnosis of Creativity Test: Torrens E. S.-Petersburg: IMATON.

Yagolkovsky L. S. (2010). Psychology of innovation: approaches, models, processes. Moscow.

Zagashev, I.O., (2010). Psychological readiness for innovation as a condition for the effectiveness of the introduction of a quality management system. Izvestiya Samara Scientific Center of the Russian Academy of Sciences. Vol. 12 (5), pp. 418-420.

Zhuravlev, A. L., \& Kupreychenko, A. B. (2007). Economic self-determination: theory and empirical research. Moscow: Institute of Psychology. 